Kompass

Pneumologie

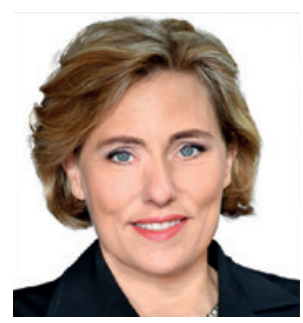

Hortense Slevogt

Zentrum für Innovationskompetenz (ZIK) Septomics, Universitätsklinikum Jena, Jena, Deutschland

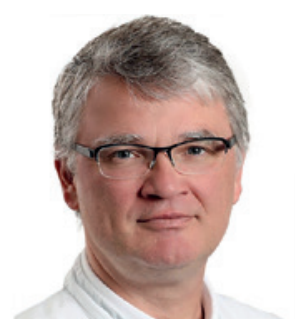

\section{Torsten Bauer}

Klinik für Pneumologie, Lungenklinik Heckeshorn, Helios Klinikum Emil von Behring, Berlin, Deutschland

\title{
Von Alpha bis Omikron: Das 3. Jahr der COVID-19-Pandemie
}

In diesem Januar 2022 schreiben wir das 3. Jahr der COVID-19-Pandemie. Bisher kam es weltweit zu 330 Millionen dokumentierten Infektionen und die Ausbreitung des Virus forderte bisher etwa 5,6 Millionen Todesopfer. Während dieser Zeit hat sich abgezeichnet, dass eine COVID-19-Infektion in einigen Aspekten deutlich anders verläuft als andere Virusinfektionen, die den Respirationstrakt betreffen und ebenfalls einen schweren Verlauf nehmen können.

In dieser Ausgabe des Kompass Pneumologie beschreiben Thomas Fuehner et al. in einer Fallserie das bemerkenswerte Symptom der «stillen Hypoxie». Bemerkenswert an dieser Symptomatik ist, dass Patienten mit ausgeprägter Hypoxie bei COVID19-Pneumonie oft deutlich weniger das Symptom «Luftnot» angeben, als Patienten, die eine vergleichbare Einschränkung ihrer Sauerstoffsättigung haben. Daran anknüpfend stellen Lisa Hentsch et al. die bisher zu diesem Thema verfügbaren Arbeiten in einem Übersichtsartikel dar. Die Autoren stellen die Hypothese auf, dass diese «stille Hypoxie» möglicherweise auf einen durch das Virus verursachten hirnorganischen Schaden hinweisen könnte. Auch andere Arbeiten hatten schon über deutliche Hinweise auf hirnbezogene Pathologien bei COVID-19-Patienten berichtet, von denen einige eine Folge des viralen Neurotropismus sein könnten. Daher steht zu Beginn dieser Ausgabe der wichtige Appell von Hentsch et al. für die Notwendigkeit weitere Forschungsarbeiten zu diesem Thema durchzuführen.

Von Stefanie Keymel wird in ihrem Wissenstransfer mit dem multisymptomatischen Entzündungssyndrom bei Erwachsenen (multisymptom inflammatory syndrome in adults (MIS-A)) auf einen weiteren besonderen Symptomenkomplex hingewiesen, der bei einer Infektion mit SARS-CoV-2 auftreten kann. Dabei handelt es sich um eine zwar seltene, aber besondere und bedrohliche Verlaufsform, die ein ernstes Gesundheitsproblem darstellen kann.

Eine weitere Besonderheit einer Infektion mit SARS-CoV-2, die Eosinopenie, wird von Panagiota Xanthouli in den Fokus genommen. Dabei kann ein Nachweis einer Eosinopenie nicht nur ein früher Hinweis auf eine SARS-CoV-2-Infektion sein, sondern auch die Gefahr eines schweren Verlaufes prognostizieren.

In der 2. Erkrankungsphase der COVID-19Infektion, in der oftmals eine Überstimulation des Immunsystems für die Pathophysiologie der Infektion von Bedeutung ist, hat eine antiinflammatorische Therapie mit Kortikosteroiden einen wichtigen Stel- 
lenwert. Stefan Krüger geht in seinem Beitrag auf eine Therapie mit niedrig dosiertem Kortikosteroid ein.

Seit Mai 2021 lernen wir, das griechische Alphabet in Zeiten der Pandemie neu zu definieren. Wir nutzen seine Buchstaben jetzt dafür, die Coronavirus-Varianten zu benennen, die seit dem Beginn der Pandemie entstanden sind. Die einzelnen Virus-
Varianten können sich in ihrer Infektiosität und der von ihr induzierten Schwere der Erkrankung unterscheiden. Daher münden die in dieser Ausgabe dargestellten neuen Erkenntnisse in einer weiteren wichtigen neuen Forschungsfrage: Nämlich ob und in welchem Maße die verschiedenen Varianten in ihrer Pathogenese unterschiedlich zu betrachten sind. Auch zu diesem Thema ist der Aufruf von Hentsch et al. zu mehr COVID-19-fokussierter Forschung wichtig. Deren Ergebnisse werden uns dabei unterstützen, die Symptome und die Pathogenese dieser Infektion besser zu verstehen.

Prof. Dr. Hortense Slevogt

Prof. Dr. Torsten Bauer 